\title{
Ecological and Phytosanitary Monitoring of Indoor Air Quality in Preschool Institutions of Novosibirsk
}

\author{
Natalia Tsybulya ${ }^{1, *}$, Elvina Fedorenko ${ }^{2}$, and Liliya Gribkova $^{3}$ \\ ${ }^{1}$ Central Siberian Botanical Garden, Novosibirsk, Russia \\ ${ }^{2}$ Tomsk State University, Tomsk, Russia \\ ${ }^{3}$ Kindergarten No. 195, Novosibirsk, Russia
}

\begin{abstract}
Special assortment of plants demonstrating high antimicrobial activity was tested in the play rooms of kindergartens in Novosibirsk. Preliminary laboratory experiments revealed universal activity of these plant species against test objects: Staphylococcus epidermidis, Escherichia coli, Candida albicans. Microbial pollution of air in the play rooms of 12 kindergartens in Novosibirsk was monitored taking into account the presence or absence of plants in the rooms. The dynamics of microbial pollution of the rooms was studied: the composition and number of colonyforming units per $1 \mathrm{~m}^{3}\left(\mathrm{CFU} / \mathrm{m}^{3}\right)$, the fractions of opportunistic pathogenic microfrlora (staphylococcus, enterobacteria). The plants with the leaf area $1.5-3.0 \mathrm{~m}^{2}$ per $100 \mathrm{~m}^{3}$ of the room volume caused a significant effect of volatile exo-metabolites: a decrease in total microbial pollution, a decrease in the number of opportunistic staphylococci and enterobacteria by a factor of 1.5-3.5, and in some cases a decrease in the number of saprophitic bacteria of Sarcina genus. Results of the investigation may be recommended for wide application in order to optimize the indoor conditions of kindergartens.
\end{abstract}

\section{Introduction}

The urgency of ecological phytodesign is due to the acute problems related to technogenic and microbiological air pollution and the necessity to care for the health of the population of large cities. Special attention is paid in the world to the indoor air quality in child-care centers because the microbial pollution of indoor air is the reason why various pathologies of upper air passages occupy a stable position in the list of children diseases [13]. One of the methods to improve indoor air quality is to use the assortment of tropical plants emitting volatile substances with high antimicrobial activity against opportunistic nicriflora; allergenic, thorny plants and the species with poisonous sap should be excluded. The goal of the present work was to study the effect of the volatile exo-metabolites of plants on the quantitative and qualitative composition of the microflora in the indoor air of kindergartens. This experimental study was aimed at revelation of the interaction of higher

\footnotetext{
* Corresponding author: ntsybulya@yandex.ru
} 
plants with microorganisms in light of the prophylactic technologies of the improvement of environmental sanitation with respect to the indoor air quality. The microbiological composition of indoor air in kindergartens was monitored taking into account the presence or absence of indoor plants.

\section{Materials and methods}

Microbiological examination of indoor air was carried out in 12 specialized kindergartens situated in urban regions with different ecological situations. The changes in the microbial composition of microflora in the air (total number of microbes and the fraction of opportunistic microflora) depending on the presence or absence of plants in rooms were determined by measuring the total number of colony-forming units (CFU) in 1 $\mathrm{m}^{3}$. Automatic sampling of biological aerosol was carried out using a PU-1B sampling device by means of impaction on the solid differential diagnostic nutrient medium GRM agar in five points in a room according to the standard procedure [4]. Air volume for the determination of total microbial number was 1001 , and air volume to determine the number of staphylococci was 2501 . The ratio of the permanent microflora (saprophitic microorganisms of Micrococcus, Sarcina, Bacillus genera) to temporary microflora (opportunistic bacteria of Staphylococcus genus, enterobacteria, mold fungi) was determined. Experiments were arranged either to study microbial pollution in the same room before and after installation of plants or in parallel in two identical rooms: plants were placed in one of the rooms (the experimental room), while the other room (reference room) remained without plants till the end of the experiment. Sampling of the air in the rooms of kindergartens was carried out in autumn and winter (November - February) because the highest microbial pollution is observed in Siberia during these months.

The objects of investigation were tropical and subtropical plants which were studied by us previously under laboratory conditions and exhibited high antimicrobial activity with respect to three test objects: Staphylococcus epidermidis, Escherichia coli, Candida albicans $[5,6]$. We term the plants arranged in a room as a phytomodule, which means the necessary number of phytoncide plants with definite leaf area per unit volume of room, taking into account the phytoecological conditions and types of rooms (the positions of windows with respect to cardinals, air humidity, contingent present in a room). Phytomodules occupy $5-10 \%$ of room area.

\section{Results and discussion}

Most frequently, bacteria dominating in indoor air are gram-positive opportunistic species of Staphylococcus genus and mold fungi [4,7]. Indoor air monitoring in several megalopolises in China showed that the qualitative and quantitative composition of microflora in air is unstable and variable depending on the season, time of day, meteorological conditions (wind direction, temperature, air humidity, altitude, insolation) [2]. Some authors from Poland and China stress the differences in the microflora in the indoor air of urban and rural cites and the dependence on the age composition of children in kindergartens, primary and secondary schools [8-10]. However, the problem of choosing the assortment of tropical plants and their effect on the quantitative and qualitative changes in the indoor microbial pollution (uthat is, the composition and total number of microbes) remains urgent.

Results of the quantitative determination of the total number of microbes in the absence of plants and in their presence in rooms are shown in Fig. 1. Total microbial pollution of indoor air after the installation of plants decreased by a factor of 1,5-3,5. 


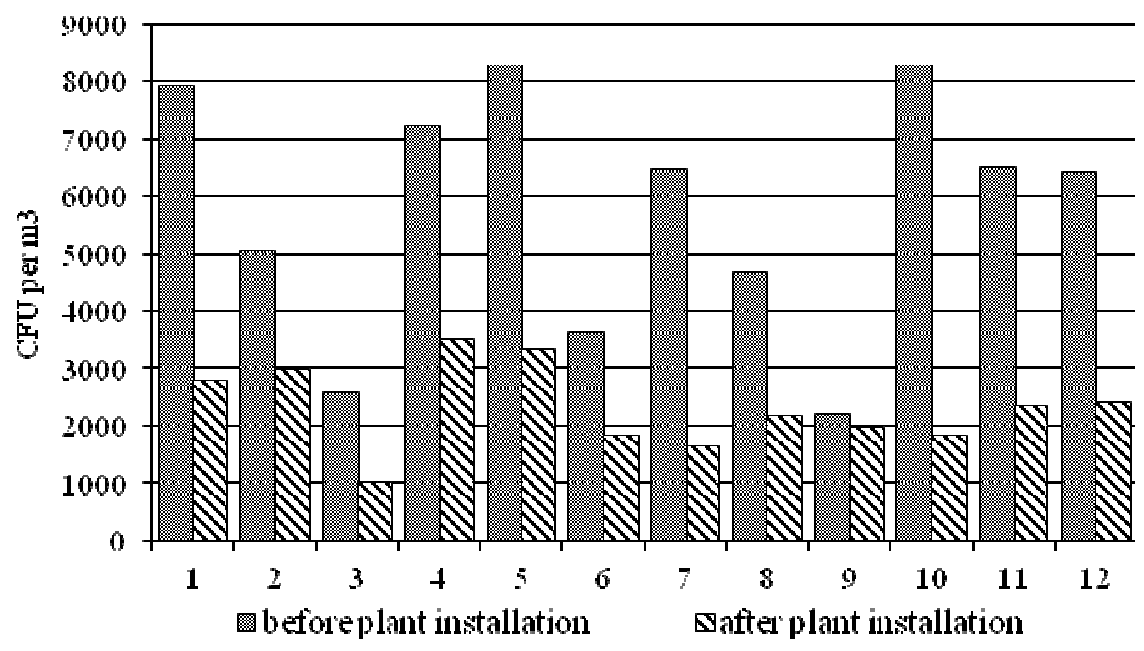

Fig. 1. Results of microbiological examination of some kindergartens in Novosibirsk before and after installation of plants.

To achieve better cogency of the efficiency of sanitizing effect of phytoncide plants, in one of the experiments the plants were installed in the room and then taken away, then again installed, and so on. After plant installation, overriding microbial pollution decreased to the normal level within 84 hours. In the absence of plants, as early as after 4 hours the total number of microbes increased from 5200 to $7500 \mathrm{CFU} / \mathrm{m}^{3}$ within 52 hours. After the next plant installation, microbial pollution did not exceed the sanitary standard during 118 hours [2].

The analysis of the qualitative changes in the mciroflora allowed us to reveal several features with respect to opportunistic microflora. The fraction of opportunistic microflora was less than $30 \%$ in rooms with plants, while in rooms without plants this parameter was 30 to $70 \%$ (Fig. 2).

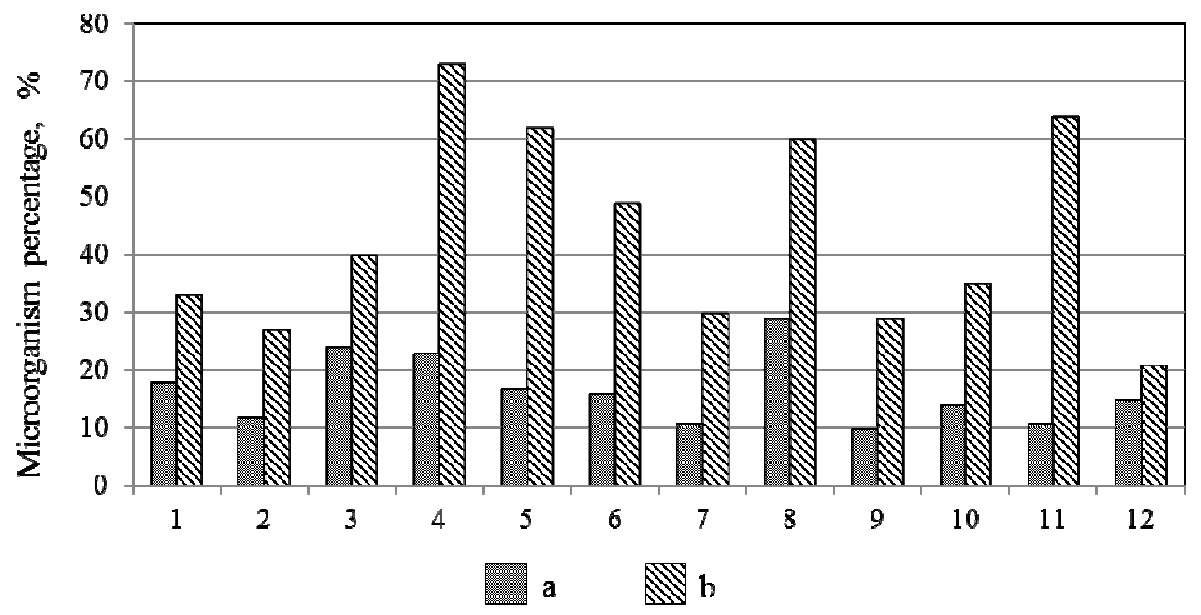


Fig. 2. The percentage of opportunistic (temporary) microflora in the air in comparison with the total number of microbes after (a) and before (b) installation of phytoncide plants.

Volatile substances emitted by plants exhibited activity against opportunistic air microflora. In the absence of plants, the percentage of the bacteria of Staphylococcus genus was 15 to $30 \%$ of the total number of microbes, while in the presence of plants it was 5 to $14 \%$ (Fig. 3a). After the installation of phytomodules in rooms, the percentage of staphylococci decreased by a factor of 1,5-3. Similar results were obtained also with respect to enterobacteria : 10 to $25 \%$ in rooms without plants, 3 to $7 \%$ in rooms with plants (Fig. $3 b)$.
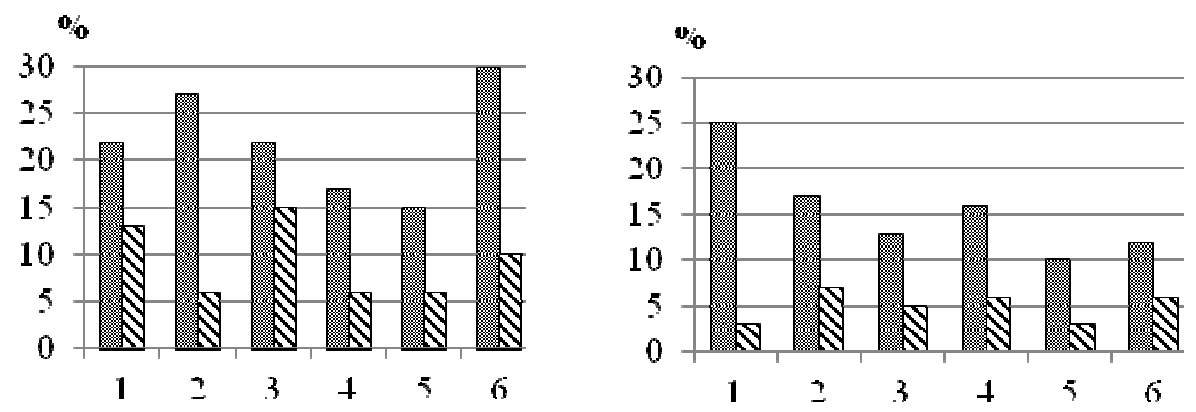

Fig. 3. Percentage of the bacteria of Staphylococcus genus (a) and enterobacteria (b) with respect to the total microbial number in the rooms of preschool institutions before and after installation of phytoncide plants.

The antimicrobial activity of the volatile emissions of Begonia carolineifolia, $B$. ricinifolia, B. boweri, B. fischeri, Eucharis grandiflora, Ficus benjamina, F. retusa, Nephrolepis exaltata, Chlorophytum comosum, Kalanchoe pinnata, K. blossfeldiana, Sansevieria trifasciata, Coleus blumei was tested in two playing rooms (reference without plants, and experiment - with plants). In this experiment, the leaf area per $100 \mathrm{~m}^{3}$ of room volume was $3,4 \mathrm{~m}^{2}$. The reference qualitative analysis of indoor air showed that the percentage of staphylococci with respect to the total number of microbes was $10 \%$, a and the percentage of saprophitic bacteria of sarcina genus was 50 to $80 \%$. After plant installation, a decrease was observed : staphylococci decreased to $5 \%$, sarcinas to $22 \%$, and total number of microbes decreased by a factor of 1,5-3,5 (Fig. 4).

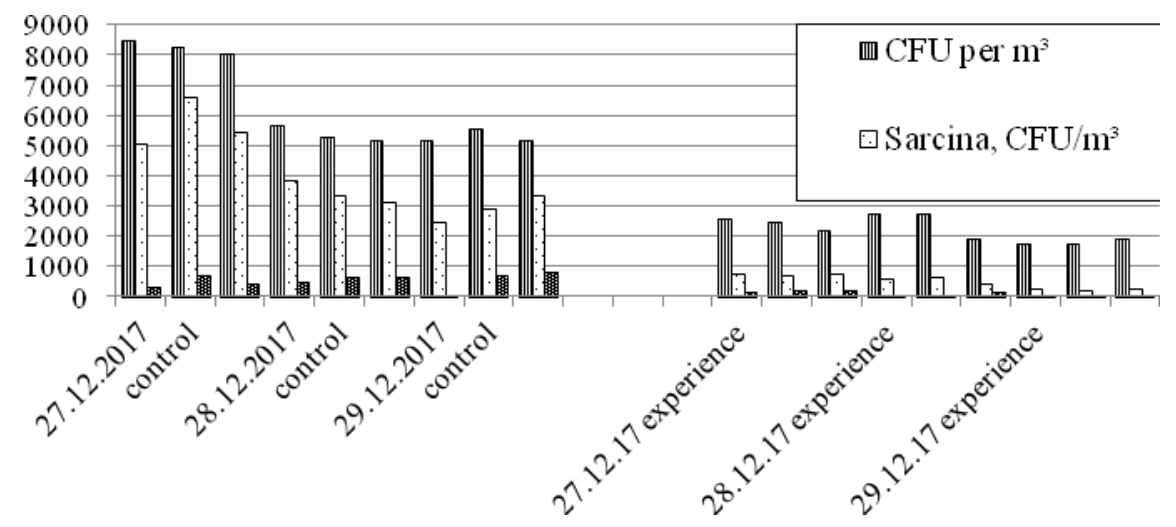


Fig. 4. Changes in the microbial composition in the reference and experimental rooms of a kindergarten after the installation of phytomodule

Experiments aimed at the studies of the antimicrobial activity of volatile plant emissions were carried out directly in rooms, so we determined the leaf area causing pronounced sanitizing effect. The total microbial pollution was studied in 12 preschool institutions; the leaf area $\left(\mathrm{S}, \mathrm{m}^{2}\right)$ was varied (Fig. 5). A stable decrease in the total number of microbes to the sanitary standard level in the rooms of kindergartens was achieved with the leaf area 1,5 $\mathrm{m}^{2}$ to $3,5 \mathrm{~m}^{2}$ per $100 \mathrm{~m}^{3}$.

$\mathrm{CFU} / \mathrm{m}^{3}$

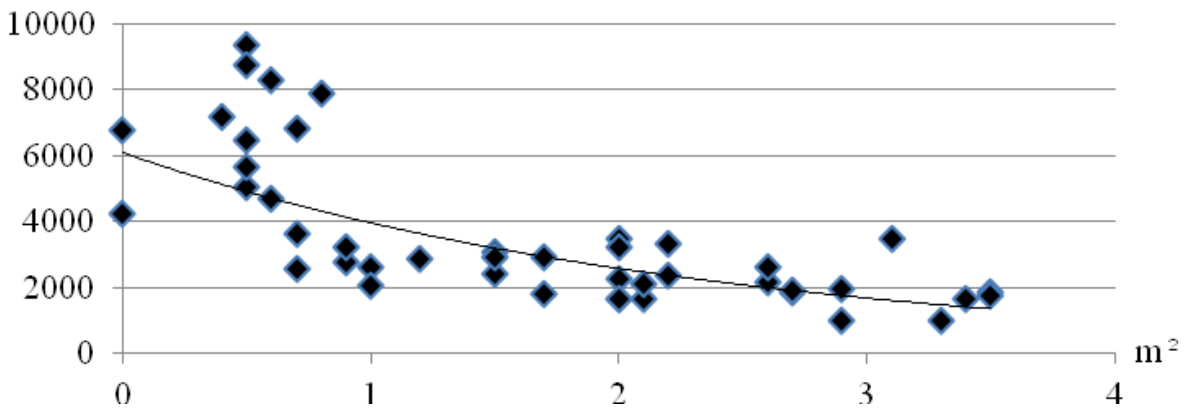

Fig. 5. The degree of microbial pollution of the indoor air in playing rooms of some kindergartens in Novosibirsk depending on the leaf area $\left(\mathrm{m}^{2}\right)$ of plants per $100 \mathrm{~m}^{3}$.

\section{Conclusion}

Investigations were carried out directly in the rooms of 12 preschool institutions; the optimal leaf area per unit volume of rooms causing the pronounced antimicrobial effect of the plants was revealed. For the plant leaf area $1.5-3 \mathrm{~m}^{2}$ per $100 \mathrm{~m}^{3}$ of room volume, the strong influence of the volatile plant exo-metabolites was observed: a decrease in total microbial pollution, a decrease in the number of opportunistic staphylococci and entorebacteria by a factor of 1.5-3.5, and in some cases a decrease in the number of saprophitic bacteria of sarcina genus. The results on the optimal relations of plant parameters to room volume may be considered as a unique science-intensive technology of indoor air sanitation with the help of antimicrobial phytomodules. These results may be recommended for wide introduction for the purpose of optimization of the conditions in the rooms of preschool institutions.

The work was carried out within the Government assignment for the Central Siberian Botanical Garden SB RAS with partial support from the Russian Foundation for Basic Research under Project No. 17-44-540601. The materials of the bioresource collection of the Central Siberian Botanical Garden SB RAS «Outdoor and Indoor Collection of Living Plants » USU 440534 were used in the investigation.

\section{References}

1. L.F. Kaznacheeva, The problem of frequent children diseases and the routed to the healthy way of life (Novosibirsk, 1990) 
2. L.H. Song, W.M. Song, W. Shi et al., J. Environ. Health 17, 135-138 (2000)

3. W. Deng, Y. Chai, H. Lin, W.W.M. So, K.W.K. Ho, A.K.Y. Tsui, R.K.S. Wong, Atmos. Environ. 128, 268-275 (2016)

4. V.V. Pokrovsky, Clinical Microbiology (GAETAR, 1999)

5. N.V. Tsybulya, T.D. Fershalova, L.P. Davidovich, Proceedings of the Samar Scientific Center of the Russian Academy of Sciences (Samara, 2017)

6. K.-Y. Guan, T.D. Fershalova, N.W. Tsybulia, D.-K Tian, Acta Botanica Yunnanica, 27, 437-442 (2005)

7. J. Olaitan, O. Adeleke, Internet J. Microbiol., 3, ispub.com/IJMB/3

8. E. Bragoszevska, A. Mainka, J.S. Pastuszka, K. Lizonczyk, Y.G. Desta, Atmos. 9, 87 (2018)

9. E. Bragoszevska, A. Mainka, J.S. Pastuszka. Atmos. 7, 142 (2016)

10. G. Zh.-G. Fan, O.Zh.-Y. Uyang, L.-F. Hu, W. X.-K. Ang, M. I. Hong, Acta Ecologica Sinica 24, 315-322 (2004) 